\author{
S.V. Syrotyuk ${ }^{1}$, Moaid K. Hussain ${ }^{2}$
}

\title{
The Effect of Cr Impurity and Zn Vacancy on Electronic and Magnetic Properties of ZnSe Crystal
}

\author{
${ }^{1}$ Lviv Polytechnic National University, Lviv, Ukraine. svsnpe@gmail.com \\ ${ }^{2} A L$-Hussain University College, Kerbala, Iraq, moaid@huciraq.edu.iq
}

\begin{abstract}
The spin-polarized electronic energy spectra of the $\mathrm{ZnCrSe}$ crystal were obtained based on calculations for a supercell containing 64 atoms. First, calculation is performed with an impurity of $\mathrm{Cr}$ atom, replacing the $\mathrm{Zn}$ atom. In the second variant, the $\mathrm{Cr}$ impurity and the vacancy at the $\mathrm{Zn}$ atom site are considered simultaneously. The results obtained in the first variant are as follows. It was found that the presence of the $\mathrm{Cr}$ atom leads to significant changes in the electronic energy bands, showing a large difference for different spin moments. The density curves of electronic states with opposite spins show an asymmetry, the consequence of which is the existence of a nonzero magnetic moment of the supercell. It was found that in the $\mathrm{ZnCrSe}$ crystal electronic $3 \mathrm{~d}$ states with spin up are present at the Fermi level, i.e. the material is a metal. For spin-down states, the material is a semiconductor in which the Fermi level is inside the band gap. The value of the direct interband gap for electronic states with spin up is equal to $1.56 \mathrm{eV}$, and the magnetic moment of the supercell is $4.00 \mu_{\mathrm{B}}$. The results obtained by the second variant of the calculation show a significant effect of the vacancy on the zinc site on the electronic structure of the $\mathrm{ZnCrSe}$ crystal. The Fermi level now intersects the dispersion curves of the upper part of the valence band for both spin orientations. The magnetic moment of the supercell is $2.74 \mu_{\mathrm{B}}$.
\end{abstract}

Keywords: A2B6, Energy Spectrum, DOS, Strongly Correlated Electrons, Hybrid Functional.

Received 19 July 2021; Accepted 25 August 2021.

\section{Introduction}

Transition metal doped II-VI chalcogenide laser materials offer a unique blend of physical, spectroscopic, and technological parameters that make them the gain media of choice for cost effective broadly tunable lasing in the mid-infrared [1] photon energy range. The II-VI semiconductor hosts provide a low phonon cut-off, broad infrared transparency, and high thermal conductivity. When doped with transition metal ions, the gain media feature a four-level energy structure, an absence of excited state absorption, broad absorption bands overlapping with many convenient fiber laser sources, a broad vibronic emission band enabling wide tunability, and high - close to $100 \%$ quantum efficiency of fluorescence at room temperature.

The structural, electrical and mid-infrared optical properties of wurtzite structured $\mathrm{ZnSe}$ nanowires with different chromium impurity distribution are investigated using first-principles calculation based on densityfunctional theory (DFT). The formation energies have been calculated to study the relative stabilities of different Cr doping positions [2].

In work [3] is reported the first room temperature gain-switched Fe:ZnSe hot-pressed ceramic laser pumped by $2.94 \mu \mathrm{m}$ radiation of mechanically Q-switched Er:YAG laser. In [4], the effect of doping of sulfur, iron and chromium on the electrical characteristics of $\mathrm{ZnSe}$ single crystals was studied. The quality of the doped crystals was inferior to that of pure $\mathrm{ZnSe}$. Volumetric transparency and morphology were studied using scanning electron microscopy to determine large defects, crystallinity and microdefects. Measured resistance and dielectric constant for all doped crystals in the frequency range from $100 \mathrm{~Hz}$ to $100,000 \mathrm{~Hz}$ indicate the use of doped $\mathrm{ZnSe}$ in tuning devices. The CrS-doped ZnSe material had the highest resistance, indicating its 
possible use in very high voltage devices.

In work [5] the characterization of energy transfer, in iron-chromium co-doped $\mathrm{ZnSe}$ middle-infrared laser crystals, is reported. The room temperature kinetics of the $\mathrm{Fe}: \mathrm{Cr}: \mathrm{ZnSe}$ sample under excitation of chromium ion at $1560 \mathrm{~nm}$ shows that energy transfer in $\mathrm{Fe}-\mathrm{Cr}$ centers could be as fast as $290 \mathrm{~ns}$.

Materials II-VI with admixtures of transitional $3 \mathrm{~d}$ elements are given considerable attention by both experimenters and theorists [6-9]. However, the available theoretical calculations of the electronic structure are preferably performed for ideal crystals or solid solutions in which the atoms of II are replaced by transition d elements. The study [10] is devoted to the optical constants evaluation of CdTe crystal heavy doped with $\mathrm{Ti}$, $\mathrm{Cr}$, and $\mathrm{Mn}$ atoms. Calculations in this work were performed in a $2 \times 1 \times 1$ supercell containing 16 atoms. In this paper, we aim to study the electronic and magnetic properties of the $\mathrm{ZnSe}$ : $\mathrm{Cr}$ crystal and the same material in the presence of a vacancy at the $\mathrm{Zn}$ atom site. Calculations are performed in a $2 \times 2 \times 2$ supercell containing 64 atoms.

\section{Calculation}

The projector augmented waves (PAW) method [11] combines the features of the pseudopotential and the allelectron method of augmented plane waves. The wave $\mid \psi_{n}>$ and pseudo-wave $\mid \tilde{\Psi}_{n}>$ functions are related as follows:

$$
\left|\psi_{n}(\mathbf{r})\right\rangle=\left|\tilde{\psi}_{n}(\mathbf{r})>+\sum_{a} \sum_{i}\left(\left|\phi_{i}^{a}(\mathbf{r})>-\right| \tilde{\phi}_{i}^{a}(\mathbf{r})>\right)<\tilde{p}_{i}^{a}\right| \tilde{\psi}_{n}>
$$

where $\left|\phi_{i}^{a}(\mathbf{r})\right\rangle$ is atomic and $\mid \tilde{\phi}_{i}^{a}(\mathbf{r})>$ pseudoatomic wave function, and $<\tilde{p}_{i}^{a} \mid$ is a projector function. The summation in (1) is performed by the augmentation spheres, which are numbered by the index $a$, and the index $i=\{n, l, m\}$ corresponds to the quantum numbers, principal, orbital and magnetic, respectively.

As can be seen from Eq. (1),

$$
\left|\psi_{n}(\mathbf{r})\right\rangle=\tau \mid \tilde{\psi}_{n}(\mathbf{r})>
$$

where the $\tau$ operator converts a pseudo-wave $\left|\tilde{\psi}_{n}(\mathbf{r})\right\rangle$ into the all-electron wave function $\left|\psi_{n}(\mathbf{r})\right\rangle$.

The explicit form of the operator follows from Eq. (1):

$$
\tau=1+\sum_{a} \sum_{i}\left(\left|\phi_{i}^{a}>-\right| \tilde{\phi}_{i}^{a}>\right)<\tilde{p}_{i}^{a} \mid .
$$

The stationary Schrödinger equation:

$$
H\left|\Psi_{n}>=\right| \Psi_{n}>\varepsilon_{n}
$$

taking into account (2) takes the following form:

$$
\tau^{+} H \tau\left|\tilde{\Psi}_{n}\right\rangle=\tau^{+} \tau\left|\tilde{\Psi}_{n}\right\rangle \varepsilon_{n}
$$

in which the required spectrum of electrons is the same as in equation (4).

The electron density in the PAW method is determined by three terms [12]:

$$
\rho(r)=\tilde{\rho}(r)+\sum_{a}\left(\rho^{a}(r)-\tilde{\rho}^{a}(r)\right),
$$

The first term is a smooth pseudo-density $\tilde{\rho}(r)$, which is represented by the Fourier transform,

$$
\tilde{\rho}(\mathbf{r})=\sum_{n \mathbf{k}} f_{n \mathbf{k}}\left|\tilde{\Psi}_{n \mathbf{k}}(\mathbf{r})\right|^{2}=\frac{1}{\Omega} \sum_{\mathbf{G}} \tilde{\rho}(\mathbf{G}) e^{i \mathbf{G} \cdot \mathbf{r}}
$$

where $f_{n \mathbf{k}}$ are the filling numbers of one-electron states, $\mathbf{k}$ is the vector from the first Brillouin zone, $n$ are the numbers of the electron-populated zones, $\Omega$ is the volume of the unit cell, $\mathbf{G}$ is the vector of the inverted lattice of the crystal.

For all electronic functions, formula (7) would look like this:

$$
\rho(\mathbf{r})=\sum_{n \mathbf{k}} f_{n \mathbf{k}}\left|\Psi_{n \mathbf{k}}(\mathbf{r})\right|^{2}=\frac{1}{\Omega} \sum_{\mathbf{G}} \rho(\mathbf{G}) e^{i \mathbf{G} \cdot \mathbf{r}}
$$

There is a very significant difference between formulas (7) and (8). It consists in the fact that equation (7) requires $\sim 10^{3}$ vectors to develop a Fourier series, while to achieve the same calculation accuracy as equation (7) they must be used in $(8) \sim 10^{6}$ vectors. Thus, the operation of the all electronic function in crystal makes problem (4) impossible to solve even on supercomputers.

The following two terms of the electron density within the augmentation sphere are determined using the projected population coefficients of the states,

$$
W_{i j}^{a}=\sum_{n \mathbf{k}} f_{n \mathbf{k}}<\tilde{\Psi}_{n \mathbf{k}}\left|\tilde{p}_{i}^{a}><\tilde{p}_{j}^{a}\right| \tilde{\Psi}_{n \mathbf{k}}>,
$$

namely:

$$
\begin{aligned}
& \rho^{a}(r)=\sum_{i j} W_{i j}^{a} \varphi_{i}^{a^{*}}(r) \varphi_{j}^{a}(r), \\
& \tilde{\rho}^{a}(r)=\sum_{i j} W_{i j}^{a} \tilde{\varphi}_{i}^{a^{*}}(r) \tilde{\varphi}_{j}^{a}(r) .
\end{aligned}
$$

The idea of the PAW method is to convert the Schrödinger equation to an equation in which an unknown state is function is $\mid \tilde{\Psi}_{n}>$. If it is found, then from the help Eq. (1) the all-electronic state function $\mid \Psi_{n}>$ is obtained. Through the latter we find the electron density and the corresponding Hartree potential.

The exchange-correlation potential was chosen in the form of PBE0 [11-14], according to which the exchangecorrelation energy has a form

$$
E_{x c}^{P B E 0}[\rho]=E_{x c}^{P B E}[\rho]+\frac{1}{4}\left(E_{x}^{H F}\left[\Psi_{3 d}\right]-E_{x}^{P B E}\left[\rho_{3 d}\right]\right),
$$

where $P B E$ corresponds to exchange-correlation functional [13], and $\Psi_{3 d}$ and $\rho_{3 d}$ represent the wave 


$$
E_{x}^{H F}\left[\Psi_{3 d}\right]=-\frac{1}{2} \sum_{n n^{\prime}}^{o c c} \delta_{\sigma_{n}, \sigma_{n^{\prime}}} \int d \mathbf{r} d \mathbf{r}^{\prime} \frac{\Psi_{n}(\mathbf{r}) \Psi_{n^{\prime}}^{*}(\mathbf{r}) \Psi_{n}^{*}\left(\mathbf{r}^{\prime}\right) \Psi_{n^{\prime}}\left(\mathbf{r}^{\prime}\right)}{\left|\mathbf{r}-\mathbf{r}^{\prime}\right|}
$$

where $n$ and $n_{-}$range over occupied correlated states and $\sigma n$ and $\sigma n_{-}$are the associated spins where $n$ and $n^{\prime}$ run over occupied correlated states, and $\sigma_{n}, \sigma_{n^{\prime}}$ are the associated spins. In the PAW basis the calculation formula takes the following form $[13,14]$ :

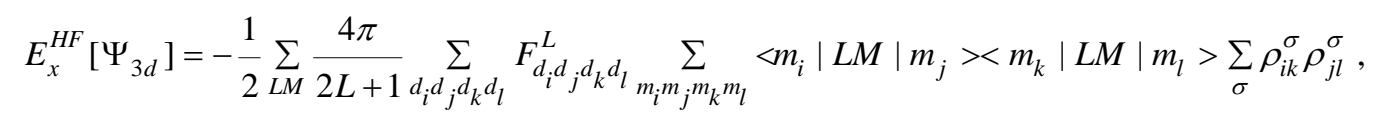

where $<m_{i}|L M| m_{j}>$ are Gaunt coefficients and $F_{d_{i} d_{j} d_{k} d_{l}}^{L}$ are the Slater integrals [14], and $\rho_{i j}^{\sigma}=\sum_{n \mathbf{k}} f_{n \mathbf{k}}<\tilde{\psi}_{n \mathbf{k}}^{\sigma}\left|\tilde{p}_{i}><\tilde{p}_{j}\right| \tilde{\psi}_{n \mathbf{k}}^{\sigma}>\quad$ is the electron density; coefficients $f_{n \mathbf{k}}$ denote the DFT occupation numbers. Indices $i, j, i=\left\{d_{i}, m_{i}\right\}$ in electron density, $\rho_{i k}^{\sigma}$, stand for $d_{i}=\left\{l_{i}, n_{i}\right\}$ for a selected $d$ orbital.

The calculations were performed for a $2 \times 2 \times 2$ supercell using the ABINIT [11] program in the PAW basis. The supercell contains 64 atoms, one of which $(\mathrm{Zn})$ in the first stage was replaced by a $\mathrm{Cr}$ atom. In the second stage, the same supercell was introduced into the calculation program, but with a vacancy at one site of the $\mathrm{Zn}$ atom. That is, first the influence of the transition $3 \mathrm{~d}$ element $\mathrm{Cr}$ on the electronic structure of the $\mathrm{ZnCrSe}$ material was studied, and then the changes in the electronic properties caused by the combined action of the substitution atom and the point defect were traced. The structure of the obtained material was optimized by the method of minimizing total energy as a function of the volume of the supercell. A spatial grid of $80 \times 80 \times 80$ was used to calculate the wave function, and $108 \times 108 \times 108$ was used for the electron density and crystal potential.

\section{Analysis of results}

The partial densities of the electronic states of $\mathrm{Zn}$, shown in Fig. 1, do not reveal significant changes due to the vacancy. However, a comparison of the density diagrams of the electronic states of $\mathrm{Cr}$ indicates a radical restructuring of their energy dependence for $3 \mathrm{~d}$ electrons. Such large changes are due to the availability of vacancies. In a crystal without a vacancy, the Fermi level intersects the dispersion curves of $3 \mathrm{~d}$ electrons with spin up, which move in the very narrow energy bands with a high density of states. That is, at the Fermi level we have strongly correlated fermions. Analyzing the partial densities of the Se states, we note that in a material without a vacancy its $p$ electrons in the spin-up states are also present at the Fermi level. The curves of the partial DOS in the material with the vacancy show dominance at the Fermi level of $3 \mathrm{~d}$ Cr electrons.
The total DOS in the material $\mathrm{ZnSe}: \mathrm{Cr}$ are shown in Fig. 2. Note that in a crystal without a vacancy, the $3 \mathrm{~d}$ levels of the $\mathrm{Zn}$ atom are localized in the energy interval $-8 \leq \varepsilon \leq-7(\mathrm{eV})$, whereas in a material with a vacancy the bounds of this interval become $-7 \leq \varepsilon \leq-6$ (eV), i.e. they shift to the region of higher energies by about $1 \mathrm{eV}$. The radical rearrangement of the DOS curves for different values of the electron spin moment is obvious.

Fig. 3 shows the spin-polarized electronic energy spectra of a $\mathrm{ZnCrSe}$ crystal without a vacancy at the $\mathrm{Zn}$ atom site (left), and with vacancy (vac, right). It is easy to see that for a spin up states the Fermi level intersects the dispersion curves of electrons in the crystal, both without a point defect and in the presence of a vacancy. For spindown, the defect-free crystal is a direct-band semiconductor, and in a crystal with a vacancy, the Fermi level is immersed in the upper part of the valence band. Thus, a non-vacant crystal is a semi-metal with a ferromagnetic ordering, i.e. it can be considered as a candidate for use in spintronics. However, the introduction of vacancies completely destroys this forecast, which is easy to see on the right side of Fig. 3. Now, there is no reason to talk about the half-metallic state, because for both spins we have semiconductors with p-type carriers.

In Fig. 3, we note that in the material without a vacancy for states with spins up, inside the band gap, around the Fermi level there are bands of $3 d$ symmetry due to the presence of $\mathrm{Cr}$ atoms. Thus, the $\mathrm{Cr}$ atoms cause very significant changes in the electronic structure of the $\mathrm{ZnCrSe}$ material compared to a pure $\mathrm{ZnSe}$ crystal. The very narrow energy bands of $3 d$ electrons appear, in which the carriers have large effective masses, i.e. heavy fermions. In the material with the vacancy, these bands correspond to electrons in the spin-down states. Their curves shifted to the lower part of the conduction band. 

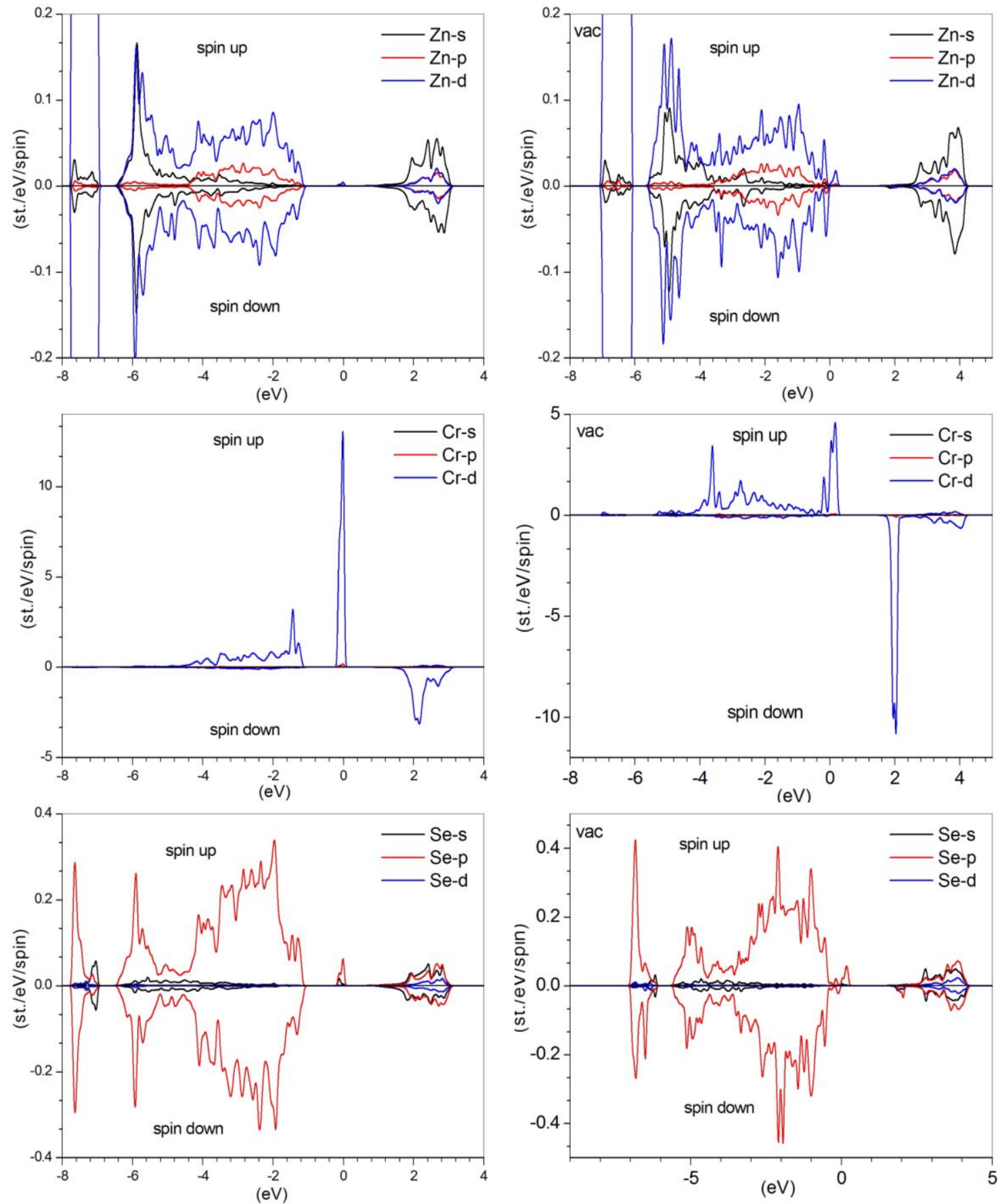

Fig. 1. Partial density of electronic states in the $\mathrm{ZnCrSe}$ crystal.
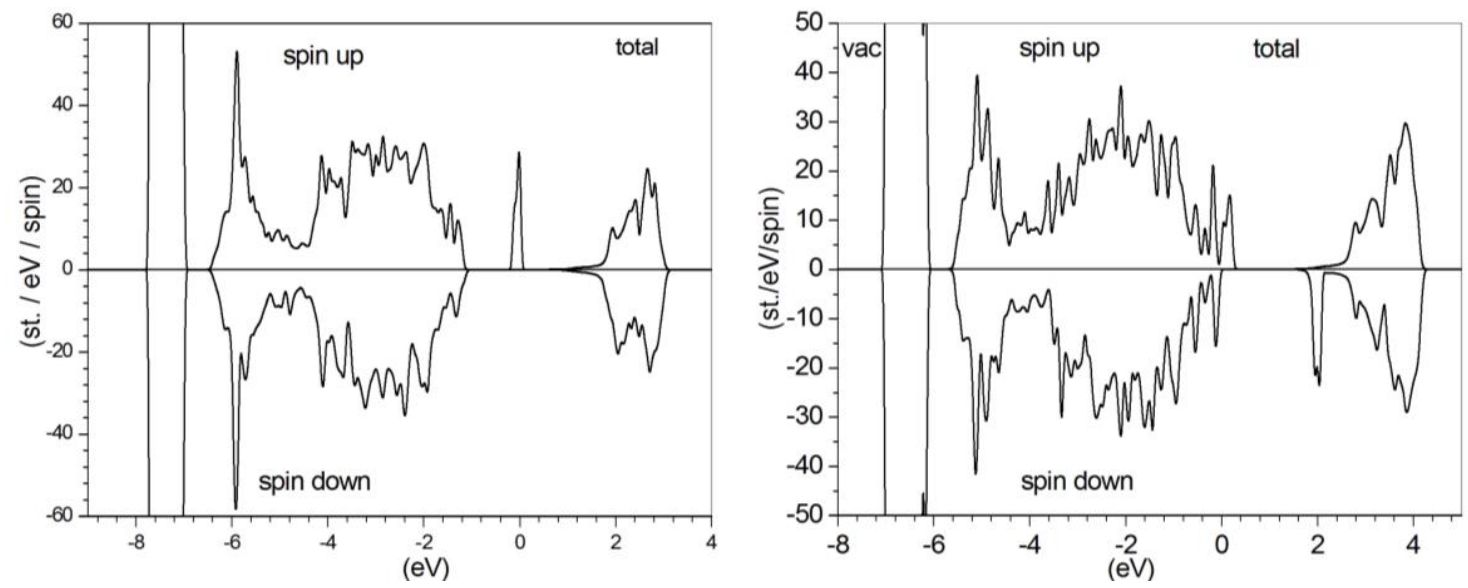

Fig. 2. Total density of electronic states in the $\mathrm{ZnCrSe}$ crystal. 

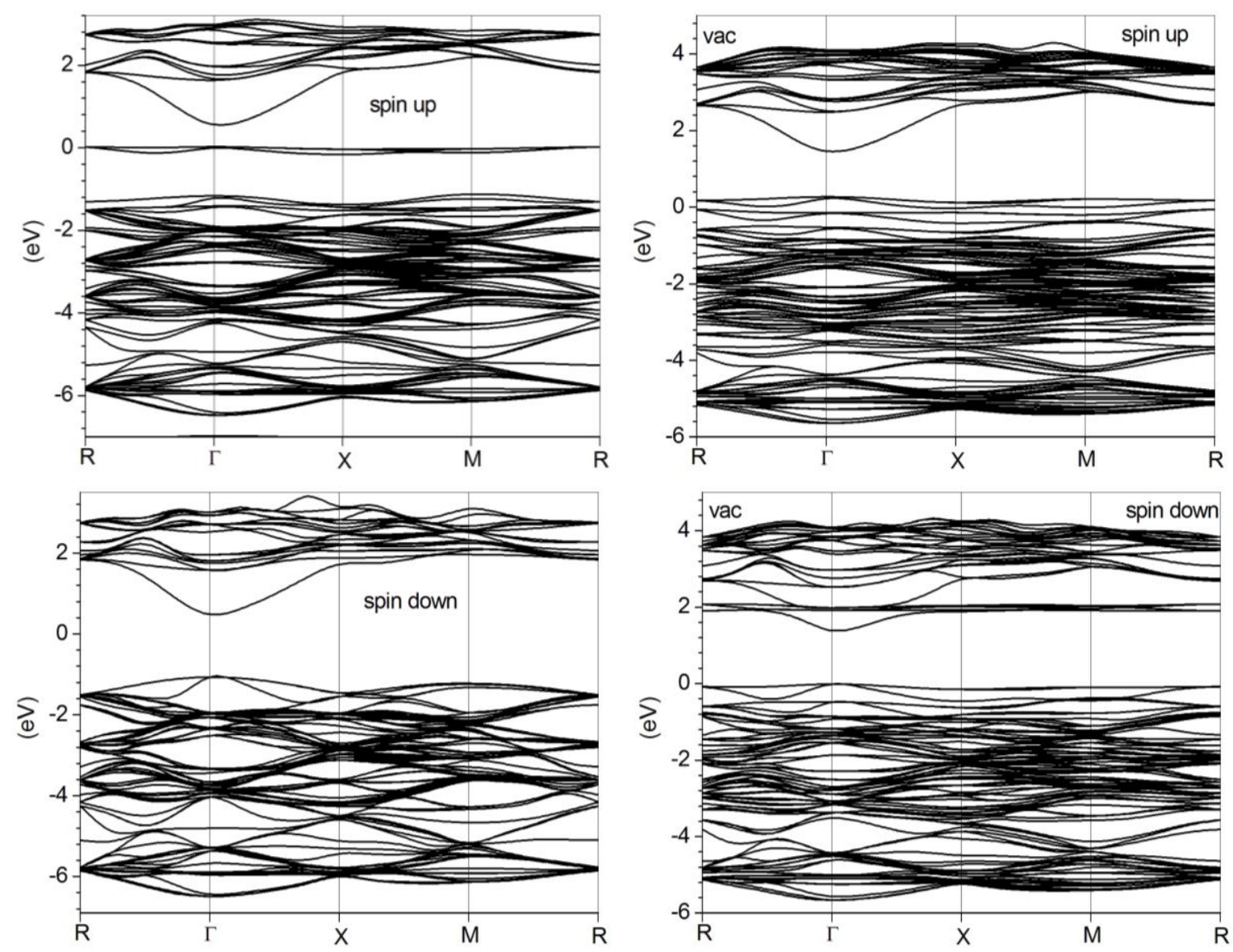

Fig. 3. The spin-polarized electronic energy bands in the $\mathrm{ZnCrSe}$ crystal.

\section{Conclusions}

The electronic energy spectra of the $\mathrm{ZnCrSe}$ system were obtained for a supercell containing 64 atoms, in which one $\mathrm{Zn}$ atom is replaced by a $\mathrm{Cr}$ atom. Calculations of the electronic structure in the same material with a point defect of the vacancy at $\mathrm{Zn}$ atom site were also performed. It was found that the $3 \mathrm{~d}$ electrons of the impurity $\mathrm{Cr}$ atom are located in a narrow energy bands, with the large DOS values. The electronic structure of the $\mathrm{ZnCrSe}$ material, without taking into account point defects in the crystal, reveals its half-metallic properties. In fact, for the spin up it is a metal, and for the spin down it is a semiconductor. Taking into account in this material the vacancy at the $\mathrm{Zn}$ atom site disavows the conclusions about the half-metallic state, because the presence of such a point defect leads to the immersion of the Fermi level in the valence band.

Syrotyuk S.V. - Ph.D., Associate Professor; Hussain M.K. - Associate Professor, PhD.

[1] S.B. Mirov, V.V. Fedorov, D.V. Martyshkin, I.S. Moskalev, et al., Proc. SPIE 9744, Optical Components and Materials XIII, 97440A, 24 February 2016. (SPIE OPTO, San Francisco, California, United States, 2016); https://doi.org/10.1117/12.2212822.

[2] Shenyu Dai, Guoying Feng, Yuqin Zhang, Lijuan Deng, Hong Zhang, Shouhuan Zhou, Results in Physics 8, 628 (2018); https://doi.org/10.1016/j.rinp.2017.12.075.

[3] K. Karki, Sh. Yu, V. Fedorov, D. Martyshkin, Sh. Subedi, Y. Wu, S. Mirov, Opt. Mater. Express 10, 3417 (2020); https://doi.org/10.1364/OME.410941.

[4] N.B. Singh, Ching-Hua Su, Fow-Sen Choa, Bradley Arnold, Puneet Gill, Charmain Su, Ian Emge, Rachit Sood, Crystals 10, 551 (2020); https://doi.org/10.3390/cryst10070551.

[5] V. Fedorov, T. Carlson, S. Mirov, Opt. Mater. Express 9, 2340 (2019); https://doi.org/10.1364/OME.9.002340.

[6] J.R. Sparks, S.C. Aro, R. He, M.L. Goetz et al., Opt. Mater. Express 10, 1843 (2020); https://doi.org/10.1364/OME.397123.

[7] Y. Zhang, Current Applied Physics, 16, 501 (2016); https://doi.org/10.1016/j.cap.2016.01.013.

[8] R.Yu. Petrus, H.A. Ilchuk, V.M. Sklyarchuk, A.I. Kashuba, I.V. Semkiv, E.O. Zmiiovska, J. Nano- Electron. Phys. 10, 06042 (2018); https://doi.org/10.21272/jnep.10(6).06042. 
[9] S.V. Syrotyuk, O.P. Malyk, J. Nano- Electron. Phys., 11, 01009 (2019); https://doi.org/10.21272/jnep.11(1).01009.

[10] H. Zaari, M. Boujnah, A. El Hachimi, A. Benyoussef, A. El Kenz, Opt. Quant. Electron., 46, 75 (2014); https://doi.org/10.1007/s11082-013-9708-y.

[11] X. Gonze et al., Comput. Phys. Comm. 205,106 (2016); https://doi.org/10.1016/j.cpc.2016.04.003.

[12] P.E. Blöchl, Phys. Rev. B 50, 17953 (1994); https://doi.org/10.1103/PhysRevB.50.17953.

[13] J.P. Perdew, K. Burke, M. Ernzerhof, Phys. Rev. Letters 77, 3865 (1996); https://doi.org/10.1103/PhysRevLett. 77.3865 .

[14] M. Ernzerhof, G.E. Scuseria, J. Chem. Phys. 110, 5029 (1999); https://doi.org/10.1063/1.478401.

\title{
С.В. Сиротюк ${ }^{1}$ М.К. Хуссейн ${ }^{2}$
}

\section{Вплив домішки Cr та вакансії Zn на електронні й магнітні властивості кристала ZnSe}

\author{
Національний університет "Львівська політехніка", Львів, Украӥна, svsnре@ gmail.com \\ Коледж університету Аль-Хуссейна, Кербала, Ірак, moaid@ huсiraq.edu.iq
}

\begin{abstract}
Поляризовані за спіном електронні енергетичні спектри кристала $\mathrm{ZnCrSe}$ отримані з розрахунків для суперкомірки, яка містить 64 атоми. У першому варіанті розрахунку домішка Cr заміщує атом Zn. У другому варіанті одночасно розглядаються домішка $\mathrm{Cr}$ та вакансія на вузлі атома $\mathrm{Zn}$. Результати першого підходу такі. Знайдено, що присутність $3 \mathrm{~d}$ перехідного елемента $\mathrm{Cr}$ приводить до значних змін у електронних енергетичних зонах, які виявляють велику відмінність для різних орієнтацій спіна. Криві густини електронних станів 3 протилежними спінами демонструють асиметрію, тобто магнітний момент суперкомірки відмінний від нуля. Виявлено, що в кристалі $\mathrm{ZnCrSe}$ електронні $3 \mathrm{~d}$ стани зі спіном вгору присутні на рівні Фермі, тобто матеріал є металом. Для станів зі спіном униз матеріал $є$ напівпровідником з рівнем Фермі всередині забороненої зони. Значення прямої міжзонної щілини для електронних станів зі спіном вгору дорівнює $1,56 \mathrm{eB}$, а магнітного моменту суперкомірки $-4,00 \mu_{B}$. Результати, отримані за другим варіантом розрахунку, виявляють значний вплив вакансії на вузлі цинку на електронну структуру кристала $\mathrm{ZnCrSe}$. Тепер рівень Фермі перетинає дисперсійні криві верхньої частини валентної зони для обидвох орієнтацій спіна. Магнітний момент суперкомірки становить $2,74 \mu_{B}$.
\end{abstract}

Ключові слова: А2В6, енергетичний спектр, сильно скорельовані електрони, гібридний функціонал. 